\title{
Potencial de controle de espécies de Piper sobre fungos fitopatogênicos
}

\begin{abstract}
A produção de feijoeiro comum (Phaseolus vulgaris) é limitada, dentre outros fatores, pela ocorrência de doenças, destacando-se a mela do feijoeiro e o mofo cinzento, causados pelos fungos Rhizoctonia solani e Sclerotium rolfsii, respectivamente. Extratos vegetais com potencial fungicida se destacam como um método alternativo no controle de fitopatógenos. 0 objetivo deste trabalho foi avaliar extratos de espécies do gênero Piper no cresciment micelial dos fungos R. solani e S. rolfsii. Foram preparados extratos aquosos e alcoólicos nas proporç̃oes de 1:10, 1:100, 1:1000 e 1:10000mg/mL, obtidos a partir de materiais secos e frescos de folhas, talos e inflorescências de P. carniconnectivum, P. hispidum, P. nigrum, P. permucronatum, P. tuberculatum e P. umbellatum, cultivadas em casa de vegetação e campo, totalizando cento e um tratamentos. A atividade antifúngica foi avaliada pelo método de difusão em poços, utilizando meio BDA. Alíquotas de $10 \mu \mathrm{L}$ dos extratos avaliados foram depositadas em cada poço, e um disco de micélio de 0,5cm de diâmetro do patógeno desafiante adicionado no centro da placa. Os halos de inibição formados foram medidos a cada $24 h$, no sentido longitudinal e transversal. Testes in vivo foram conduzidos em folhas destacadas e em plântulas de feijoeiro. Folhas destacadas de feijoeiro foram acondicionadas en caixas tipo Gerbox, e mudas de feljoeiro mantidas em câmara úmida. Sobre as folhas foram pulverizados os extratos avaliados, e apos $24 \mathrm{~h}$, uma suspensão de micélio do patogeno R. solani, na concentração de $1 \times 106$ fragmentos

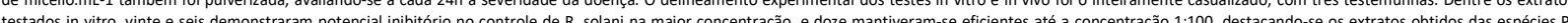
permucronatum e P. carniconnectivum. Nos ensaios com o fungo S. rolfsii, dez extratos mostraram eficiência na inibição do patógeno, destacando-se o extrato aquoso de $P$. tuberculatum na maior concentraç̃o. No ensai i . vivo com folhas destacadas dez extratos apresentaram eficiência no controle da mela do feijoeiro, sendo que os extratos obtidos a partir de P. permucronatum, P. carniconnectivum e P. nigrum apresentaram efeitos de controje semelhantes ao controle fungicida, permanecendo extratos de P. permucronatum eficientes em testes in vivo com mudas de feijão em câmara úmida. Os resultados obtidos sugerem que os extratos de espécies do eênero Piper podem vir a ser utilizados futuramente como fonte de novas moléculas bioativas, visando o controle destes patógenos.
\end{abstract}

\section{Control potential of Piper species on phytopathogenic fungi}

\begin{abstract}
The production of common bean (Phaseolus vulgaris) is limited, among other factors, by the occurrence of diseases, especially bean molasses and gray mold, caused by the fungi Rhizoctonia solani and Sclerotium rolfsii, respectively. Plant extracts with fungicidal potential stand out as an alternative method to control phytopathogens. The objective of this work was to evaluate extracts of Piper species on the mycelial growth of R. solani and $S$. (a) of the evaluated extracts were deposited in each well, and a $0.5 \mathrm{~cm}$ diameter mycelium disc of the challenging pathogen added in the center of the plate. Inhibition halos formed were measured every $24 \mathrm{~h}$ in the longt alqu transverse directions. In vivo tests were conducted on detached leaves and bean seedlings. Detached bean leaves were packed in Gerbox boxes and bean seedlings kept in a humid chamber. The extracts were sprayed on the leaves, and after $24 \mathrm{~h}$, a suspension of the pathogen R. solani mycelium at a concentration of $1 \times 106$ mycelium fragments.mL-1 was also sprayed, assessing the severity of the disease every $24 \mathrm{~h}$. The experimental design of the in vitro and in vivo tests was completely randomized, with three witnesses. Among the extracts tested in vitro, twenty-six showed inhibitory potential to control R. solani at the highest concentration, and twelve remained ffficient up to 1: 100, highlighting the extracts obtained from P. permucronatum and P. carniconnectivum species. In the trials with S. rolfsii fungus, ten extracts showed efficiency in the inhibition of the pathogen, highlighting the aqueous extract of P. tuberculatum in the highest concentration. In the in vivo test with detached leaves, ten extracts showed efficiency in the control of bean molasses, and the extracts obtained from P. permucronatum, P. carniconnectivum and P. nigrum showed control effects similar to fungicide control, while P extracts remained. Permucronatum efficient in vivo tests with wet chamber bean seedlings. The results suggest that extracts of species of the genus Piper may be used in the future as a source of new bioactive molecules, aiming at controlling these pathogens.
\end{abstract}

Keywords: Plant diseases; Bioactive compounds; Alternative control; Piperacea.

Jessica Silva Felix Bastos

Universidade Federal de Rondônia, Brasil http://lattes.cnpq.br/0634812827491159 jessicafelixbio@gmail.com

Cléberson de Freitas Fernandes Universidade Federal do Ceará, Brasil http://lattes.cnpq.br/7426209328649448 cleberson.fernandes@embrapa.br

José Roberto Vieira Junior (iD Universidade Federal de Rondônia, Brasil http://lattes.cnpq.br/9904275274067824 http://orcid.org/0000-0001-7939-8119 jose-roberto.vieira@embrapa.br

Aline Souza da Fonseca (it)

Universidade Federal de Rondônia, Brasil http://lattes.cnpq.br/0456233723446786 http://orcid.org/0000-0002-4019-3412 alinesouzadafonseca@gmail.com
Tamiris Chaves Freire (iD

Universidade Federal de Rondônia, Brasil http://lattes.cnpq.br/4372408393666360 http://orcid.org/0000-0002-8938-3751 tamirischavesfreire@gmail.com

\section{Simone Carvalho Sangi}

Universidade Federal de Rondônia, Brasil http://lattes.cnpq.br/6013814953613677 http://orcid.org/0000-0001-7365-015X simonecarvalhosangi@gmail.com

\section{Liliani Ogrodowczyk (iD)}

Universidade Federal de Rondônia, Brasil http://lattes.cnpq.br/1320894929836868 http://orcid.org/0000-0001-7497-8114 liliwczyk@hotmail.com
Karen Cristina Chaves Oliveira (iD)

Faculdades Integradas Aparício Carvalho, Brasi

http://lattes.cnpq.br/0113533111049758

http://orcid.org/0000-0002-9306-0517

chavesoliveira.kc@gmail.com

\section{Rodrigo Barros Rocha}

Universidade Federal de Viçosa, Brasil

http://lattes.cnpq.br/8295625748916004

rodrigo.rocha@embrapa.br

\section{Fábio da Silva Barbieri}

Universidade Federal Rural do Rio de Janeiro, Brasil

http://lattes.cnpq.br/3610317820362372

fabio.barbieri@embrapa.br

DOI: 10.6008/CBPC2179-6858.2018.008.0023

Referencing this:

BASTOS, J. S. F.; FERNANDES, C. F.; VIEIRA JUNIOR, J. R.; FONSECA, A. S.; FREIRE, T. C.; SANGI, S. C.; OGRODOWCZYK, L.; OLIVEIRA, K. C. C.; ROCHA, R. B.; BARBIERI, F. S.. Potencial de controle de espécies de Piper sobre fungos fitopatogênicos. Revista Ibero-Americana de Ciências Ambientais, v.9, n.8, p.260-272, 2018. DOI:

http://doi.org/10.6008/CBPC2179-6858.2018.008.0023 


\section{INTRODUÇÃO}

O feijão comum (Phaseolus vulgaris) está entre os alimentos mais antigos da história da humanidade. Rico em proteínas, minerais, carboidratos, fibra alimentar e vitaminas do complexo B (LAJOLO et al., 1996), é um dos alimentos mais populares no Brasil, compondo parte da dieta alimentar da população, e constituise em uma das principais fontes de proteína vegetal de seus assíduos consumidores (MIRANDA et al., 2013; GONÇALVES et al., 2015).

O cultivo de feijão sofre com limitações causadas por diversos fatores, dos quais podemos destacar as doenças, visto que a cultura é suscetível a vários patógenos, que reduzem a produtividade e afetam a qualidade do grão (CAMPOS et al., 2015). Entre as doenças que acometem o cultivo do feijoeiro destacamse as causadas por fungos, que são as mais comuns para a redução da produção (RIBEIRO et al., 2011).

A mela do feijoeiro também conhecida como murcha de teia micélica, é causada pelo fungo descrito como Thanatephorus cucumeris (Frank) Donk em sua fase perfeita (Rhizoctonia solani Kuhn fase imperfeita) (COSTA et al., 2008). Os sintomas consistem em manchas que causam a necrose das folhas e consequentemente a desfolha das plantas (NECHET et al., 2007). Já a podridão do colo é causada pelo fungo Sclerotium rolfsii Sacc (fase perfeita Aetholia rolfsii (Curzi) Tu e Kimbr) sendo a doença letal para a planta infectada independente do seu estádio fenológico (SARTORATO et al., 1994; VALE et al., 1997).

O controle de fitopatógenos em geral na agricultura vem sendo realizado por meio de agrotóxicos durante anos no Brasil, estes apresentam economia e eficácia ao produtor, o que torna a produção agrícola cada vez mais dependente desses produtos (SILVA et al., 2014; ABRASCO, 2012). O uso indiscriminado de agrotóxicos vem causando consequências graves para o meio ambiente e para a saúde humana, decorrentes de seu uso inadequado e excessivo (MIORIN et al., 2016).

Preocupações com fatores de contaminação em geral tem levado a busca por métodos alternativos para o desenvolvimento de cultivos mais sustentáveis e menos dependentes da utilização de agrotóxicos (FERREIRA et al., 2014). As plantas apresentam um metabolismo capaz de produzir inúmeras substâncias químicas variáveis (SANTOS, 2015). Essa diversidade de moléculas existentes nas plantas gera possibilidades de descobertas de novas substâncias com potencial antifúngico (CELOTO et al.; 2008).

Espécies do gênero Piper são amplamente utilizadas, ao longo dos anos, na medicina popular por apresentarem propriedades citotóxica, antitumoral, sedativa, analgésica, larvicida, inseticida entre outras, que fazem com que partes vegetativas de Piper sejam comercializadas como produtos tradicionais fitoterápicos (SANTOS et al., 2012; SILVA et al., 2016). Estudos que visem identificar potenciais agentes de controle de fitopatógenos se apresentam como importantes instrumentos de descoberta de compostos biologicamente ativos. O presente trabalho teve por objetivo a identificação de extratos vegetais de plantas do gênero Piper como potenciais agentes no controle de fungos fitopatogênicos de importância para a agricultura. 


\section{MATERIAL E MÉTODOS}

O estudo foi realizado no laboratório de Fitopatologia e em casa de vegetação da Empresa Brasileira de Pesquisa Agropecuária/Centro de Pesquisa Agroflorestal de Rondônia, localizada no município de Porto Velho. As coletas das espécies de Piper foram realizadas no período de outubro a dezembro de 2016 com registro no SisGen sob o código A088959. Foram utilizados extratos aquosos e alcoólicos, preparados com materiais secos e frescos, de folhas, talos e inflorescências de seis espécies de Piper, sendo: Piper carniconnectivum, Piper hispidum, Piper nigrum, Piper permucronatum, Piper tuberculatum e Piper umbellatum, cultivadas em casa de vegetação e em campo experimental, totalizando cento e um extratos.

\section{Preparação dos extratos}

As espécies foram coletadas e dessas separou-se folhas, talos e inflorescências (quando havia). Para os extratos com materiais vegetais secos, estes foram secos em estufa com circulação de $\operatorname{ar}\left(65^{\circ} \mathrm{C}, 72 \mathrm{~h}\right)$ e triturados separadamente em moinho de facas, até a obtenção de um pó. Para a obtenção dos extratos com materiais vegetais frescos, as partes vegetais separadas foram maceradas com nitrogênio líquido até a obtenção de um pó homogêneo e fino.

Para o preparo dos extratos, foram utilizados $1 \mathrm{~g}$ de material vegetal para $10 \mathrm{~mL}$ do solvente (água mineral e álcool, para extratos aquosos e alcoólicos, respectivamente). A suspensão foi transferida para Erlenmeyer e levados à agitação em Incubadora Shaker refrigerada $\left(24^{\circ} \mathrm{C}, 100 \mathrm{RPM}, 24 \mathrm{~h}\right)$. Após esse período, o extrato foi filtrado com o auxílio de gaze e tecido nylon, armazenados em frascos de vidro do tipo penicilina, selados e mantidos em congelador até a utilização em experimentos in vitro e in vivo conforme metodologia adaptada (FERRIS et al., 1999).

\section{Obtenção dos isolados dos patógenos e Ensaios de antibiograma (testes in vitro)}

Os isolados dos fungos Rhizoctonia solani e Sclerotium rolfsii utilizados nos experimentos in vitro e in vivo são oriundos de folhas e talos de feijoeiro comum (Phaseolus vulgaris L.) e encontram-se preservados no laboratório de fitopatologia da Embrapa Rondônia. A atividade antifúngica dos extratos $(0,01 \mathrm{mg} / \mathrm{mL})$ foi testada utilizando o método de difusão em poços, em placas de Petri contendo meio BDA semissólido.

Após a solidificação, foram feitos poços com $0,5 \mathrm{~cm}$ de diâmetro, equidistantes no meio de cultura, e em cada um deles foi adicionado $10 \mu \mathrm{L}$ do tratamento. Em seguida, disco de micélio $(0,5 \mathrm{~cm}$ de diâmetro) do patógeno foi adicionado no centro da placa. As placas foram vedadas e colocadas em incubadora tipo B.O.D., com condições controladas $\left(25 \pm 2^{\circ} \mathrm{C}, 12 \mathrm{~h}\right.$ claro/12h escuro).

A análise dos resultados ocorreu por meio de observação dos halos de inibição que se formavam no entorno do tratamento eficiente, a partir de 24 horas após a incubação, medindo o diâmetro dos halos no sentido longitudinal e transversal (D1 e D2) utilizando um paquímetro digital. A observação dos halos de inibição do crescimento micelial com os tratamentos testados foram comparados com o grupo controle, 
contendo água, álcool 96\% e fungicida Azoxistrobina (0,6g/L) para o fungo Rhizoctonia solani e Tiabendazol $(2 \mathrm{~mL} / \mathrm{L})$ para Sclerotium rolfsii.

\section{Diluição seriada}

Os extratos que apresentaram potencial de inibição dos fungos foram submetidos à diluição seriada, com a finalidade de identificar as menores concentrações bioativas. Partindo-se do extrato inicial $(0,01 \mathrm{mg} / \mathrm{mL})$, foram preparadas diluições nas concentrações 1:10, 1:100; 1:1000 e 1:10000. Ensaios de antibiograma com as concentrações obtidas foram realizados conforme descrito anteriormente, com o objetivo de identificar a menor fração ativa.

\section{Ensaios em folhas destacadas}

O potencial de controle dos extratos foi avaliado em ensaio de folhas destacadas de feijoeiro comum, com 11 dias após o plantio. As folhas foram coletadas, lavadas com água destilada, secas com papel toalha e armazenadas em caixas do tipo Gerbox de $11,5 \mathrm{~cm}^{2}$, com esponja, papel filtro de $10 \mathrm{~mm}$ cada e uma tela preta de $8 \mathrm{~cm}^{2}$, umedecida com $15 \mathrm{~mL}$ de água destilada para manutenção da umidade das folhas (DHINGRA et al., 1995).

Para a inoculação pulverizou-se, com o auxílio de um borrifador, $250 \mu \mathrm{L}$ dos extratos sobre as folhas até a cobertura total da área foliar, em seguida levadas à incubadoras tipo B.O.D. $\left(25 \pm 2^{\circ} \mathrm{C}, 24 \mathrm{~h}, 12\right.$ horas claro/escuro). Após esse período, aplicou-se nas folhas $250 \mu \mathrm{L}$ de suspensão de micélios, ajustadas à concentração de $1.10^{6}$ frag.micélios. $\mathrm{mL}^{-1}$ em toda a face da folha. Em seguida as caixas de Gerbox foram fechadas e novamente incubadas na B.O.D. A avaliação foi realizada diariamente, por meio de fotografias das folhas com o auxílio de uma câmera digital, e avaliadas através do Programa AFsoft ${ }^{\circledR}$. O experimento foi encerrado oito dias após a incubação das folhas inoculadas, quando a severidade da doença nos controles com álcool (96\%) e água atingiram seu auge.

\section{Ensaios em câmara úmida}

O cultivo do feijoeiro foi feito em copos plásticos com capacidade para $500 \mathrm{~mL}$, contendo solo devidamente autoclavado $\left(121^{\circ} \mathrm{C}\right)$, para evitar contaminação por microrganismo. Colocou-se 3 sementes por copo onde estas foram cobertas por uma camada de solo. Os ensaios in vivo com o fungo $R$. solani foram realizados com plantas de feijoeiro com 14 dias de plantio. Primeiramente foi feita a pulverização nas folhas primarias das plantas, com o auxílio de um borrifador, dos extratos que apresentaram resultados satisfatórios nos testes in vitro e em folhas destacadas (Gerbox), considerando três controles (água, álcool 96\% e fungicida Azoxistrobina $0,6 \mathrm{~g} / \mathrm{L}$ ). Após 24 horas foi borrifado nas mesmas folhas das mudas de feijoeiro a suspensão de fragmentos de micélios do patógeno $\left(1.10^{6}\right.$ frag.micélios. $\left.\mathrm{mL}^{-1}\right)$. A severidade da doença sobre as folhas foi avaliada a partir de 24 horas após a inoculação do patógeno, com o auxílio de uma escala diagramática. 


\section{Delineamento Experimental}

Os dados obtidos nos ensaios foram submetidos à análise de variância - ANOVA, para avaliação da existência de pelo menos um extrato com potencial efeito biológico, mensurado a partir do percentual de inibição de crescimento micelial. Em todos os testes, comparação das médias de tratamentos foi realizada utilizando o teste de Scott Knott a 5\% de probabilidade. O teste de Scott Knott pode ser considerado um teste de agrupamento de médias, pois permite a classificação das médias de tratamentos sem a ocorrência de sobreposição entre os grupos (Pimentel Gomes, 2000). Foi utilizado o delineamento inteiramente casualizado com 4 repetições para os testes in vitro e 6 repetições para os testes in vivo. As análises estatísticas dos testes in vitro e in vivo, foram realizadas utilizando o programa XLSTART versão 19.03.

\section{RESULTADOS}

\section{Ensaio de antibiograma}

Dos 101 extratos avaliados, 26 apresentaram eficiência de inibição do crescimento micelial do fungo $R$. solani superior ao controle fungicida, destes destacam-se os extratos alcoólicos de talo, preparados com materiais secos de $P$. permucronatum, os extratos alcoólicos preparados com materiais vegetais secos de talos, cultivados nos dois locais, e de inflorescência de $P$. carniconnectivum, que apresentaram halos de inibição com média superior à $780 \mathrm{~mm}^{2}$ (figura 1 ).

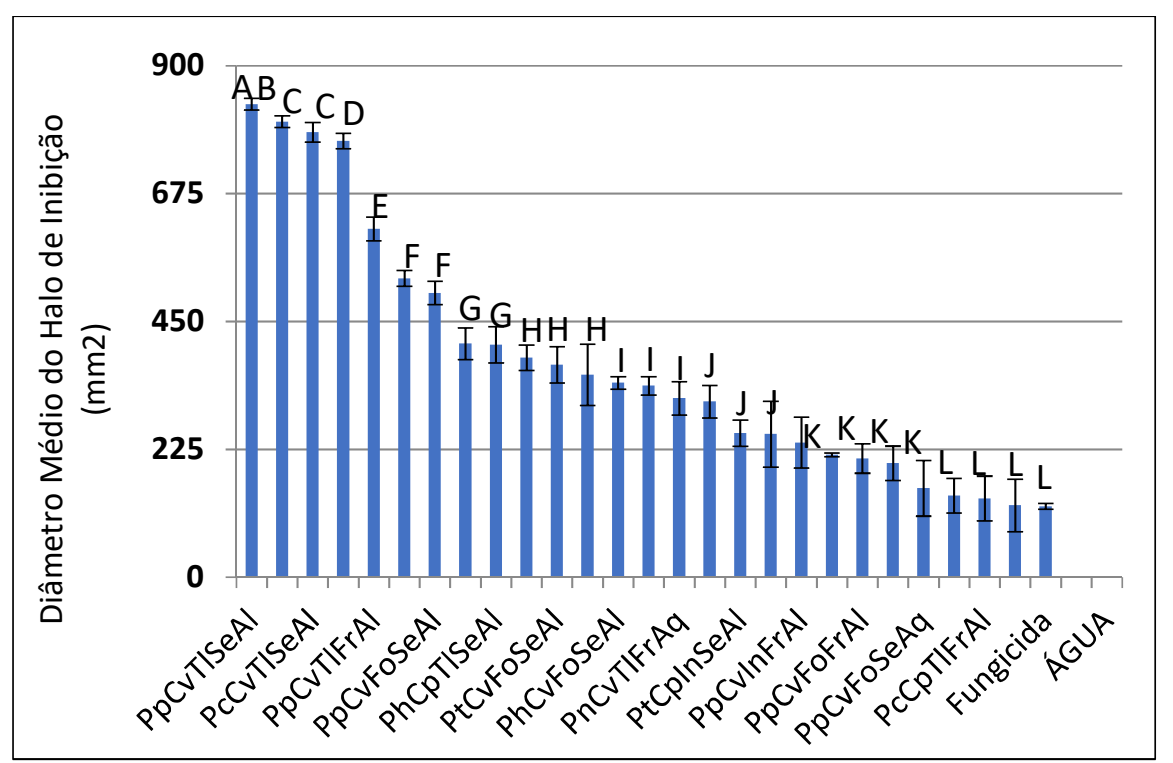

Figura 1: Efeito dos diferentes extratos de Piper sobre a inibição de $R$. solani. Valores médios seguidos de mesma letra na coluna não são diferentes baseados no teste Scott-Knott a 5\% de probabilidade. Legenda: Pp: $P$. permucronatum, Pc: P. carniconnectivum, Ph: P. hispidum, Pt: P. tuberculatum, Pu: P. umbellatum, Pn: P. nigrum; Cv: Casa de vegetação, Cp: Campo; TI: talo, Fo: folha, In: Inflorescência; Se: secos, Fr: frescos; Al: Alcoólico, Aq: Aquoso.

Nos testes com o fungo S. rolfsii, dos 101 extratos avaliados, dez apresentaram halos de inibição do crescimento micelial do patógeno, superior ao fungicida Tiabendazol, destacando-se o extrato aquoso do talo de $P$. tuberculatum preparado na forma seco cultivada em campo experimental, proposto na figura 2, que foi denominada 'Efeito dos diferentes extratos de Piper sobre a inibição de Sclerotium rolfsii. Valores 
médios seguidos de mesma letra na coluna não são diferentes baseados no teste Scott-Knott a $5 \%$ de probabilidade'.

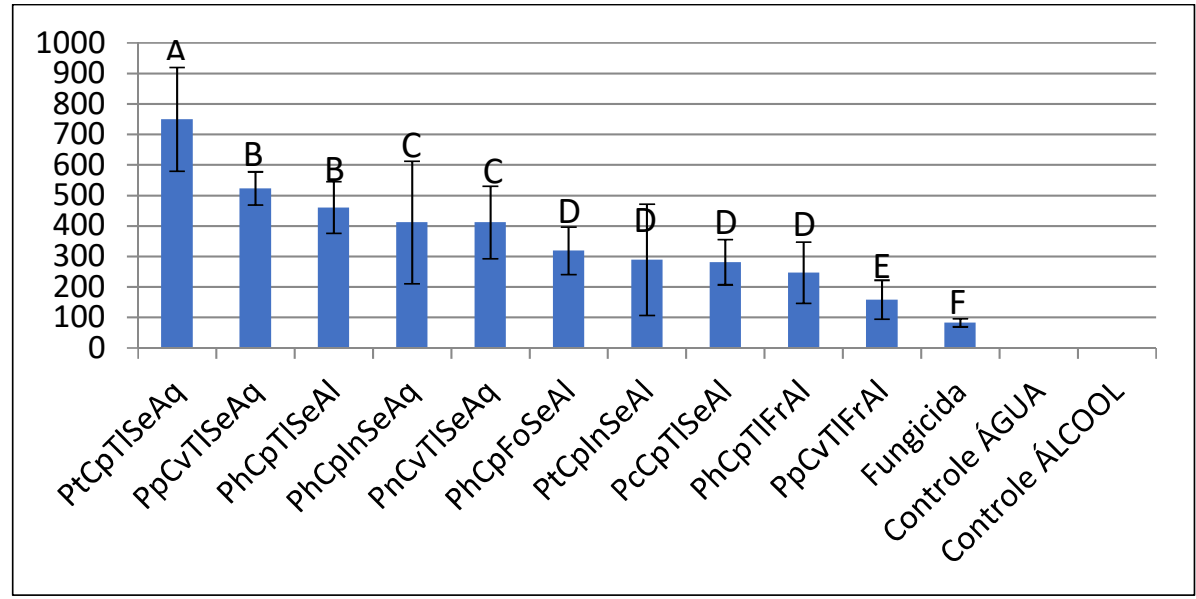

Figura 2: Efeito dos diferentes extratos de Piper sobre a inibição de Sclerotium rolfsii. Valores médios seguidos de mesma letra na coluna não são diferentes baseados no teste Scott-Knott a 5\% de probabilidade. Legenda: Pp: $P$. permucronatum, Pc: P. carniconnectivum, Ph: P. hispidum, Pt: P. tuberculatum, Pn: P. nigrum; Cv: Casa de vegetação, Cp: Campo; Tl: talo, Fo: folha, In: Inflorescência; Se: secos, Fr: frescos; Al: Alcoólico, Aq: Aquoso.

\section{Ensaios com diluição}

Nos ensaios de antibiograma fúngico com os extratos diluídos, 12 extratos apresentaram potencial inibitório até a concentração 1:100 no controle de $R$. solani. Os extratos alcoólicos de talo e inflorescência de P. carniconnectivum e extrato de talo de P. permucronatum se mantiveram como os melhores em potencial inibitório (figura 3). Nas demais diluições nenhum extrato inibiu o patógeno. Nos testes com o fungo S. rolfsii os extratos confirmaram seu controle de inibição na maior concentração 1:10, não sendo eficientes quando submetidos a diluição (dados não mostrados).

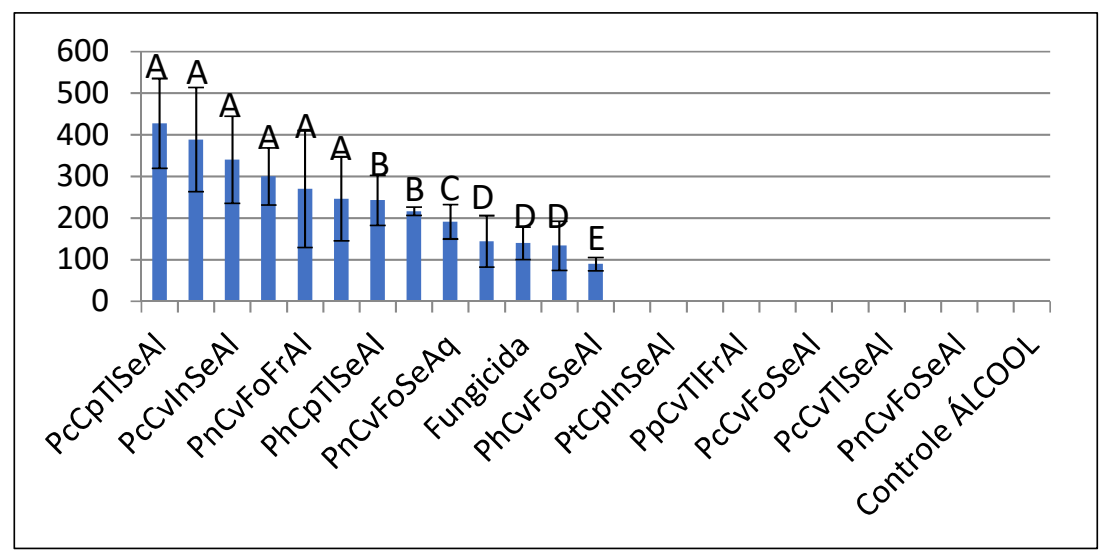

Figura 3: Percentual de halos de inibição dos extratos com concentrações de 1:100 no controle do fungo Rhizoctonia solani. Valores médios seguidos de mesma letra na coluna não são diferentes baseados no teste Scott-Knott a $5 \%$ de probabilidade. Legenda: Pp: $P$. permucronatum, Pc: $P$. carniconnectivum, $\mathrm{Ph}: P$. hispidum, $\mathrm{Pt}$ : $P$. tuberculatum, $\mathrm{Pn}: P$. nigrum; Cv: Casa de vegetação, Cp: Campo; Tl: talo, Fo: folha, In: Inflorescência; Se: secos, Fr: frescos; Al: Alcoólico, Aq: Aquoso.

\section{Ensaios em folhas destacadas}

A fim de facilitar o experimento em folhas destacadas e para melhor acondicionamento das caixas do tipo Gerbox em incubadora, ele foi dividido em duas etapas, cada etapa com um grupo controle. Foi 
constatada a eficiência dos tratamentos no controle da severidade da mela do feijoeiro, quando comparados com os controles água e álcool $96^{\circ} \mathrm{C}$. No primeiro ensaio destaca-se o extrato alcoólico de folha preparado de forma fresco de $P$. permucronatum que não diferenciou do controle fungicida (Figura 4).

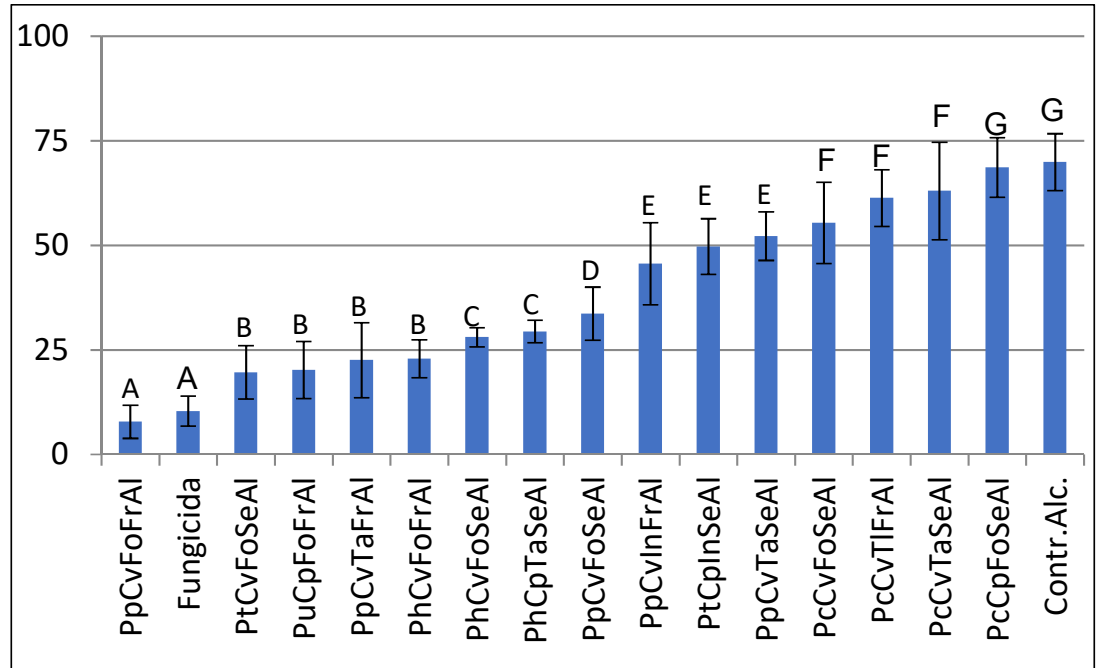

Figura 4: Severidade da mela do feijoeiro avaliado em folhas de feijão inoculadas em gerbox no 1 을 teste. Valores médios seguidos de mesma letra na coluna não são diferentes baseados no teste Scott-Knott a $5 \%$

de probabilidade. Legenda: Pp: P. permucronatum, Pc: P. carniconnectivum, Ph: P. hispidum, Pt: $P$. tuberculatum, Pu: P. umbellatum; Cv: Casa de vegetação, Cp: Campo; Tl: talo, Fo: folha, In: Inflorescência; Se: secos, Fr: frescos; Al: Alcoólico.

No segundo ensaio o extrato alcoólico preparado com materiais vegetais secos da folha de $P$. nigrum cultivado em casa de vegetação, foi o tratamento que apresentou melhor controle da severidade da doença, proposto na figura 5, que foi denominada 'Severidade da mela do feijoeiro avaliado em folhas de feijão inoculadas em gerbox no 20 teste. Valores médios seguidos de mesma letra na coluna não são diferentes baseados no teste Scott-Knott a 5\% de probabilidade'.

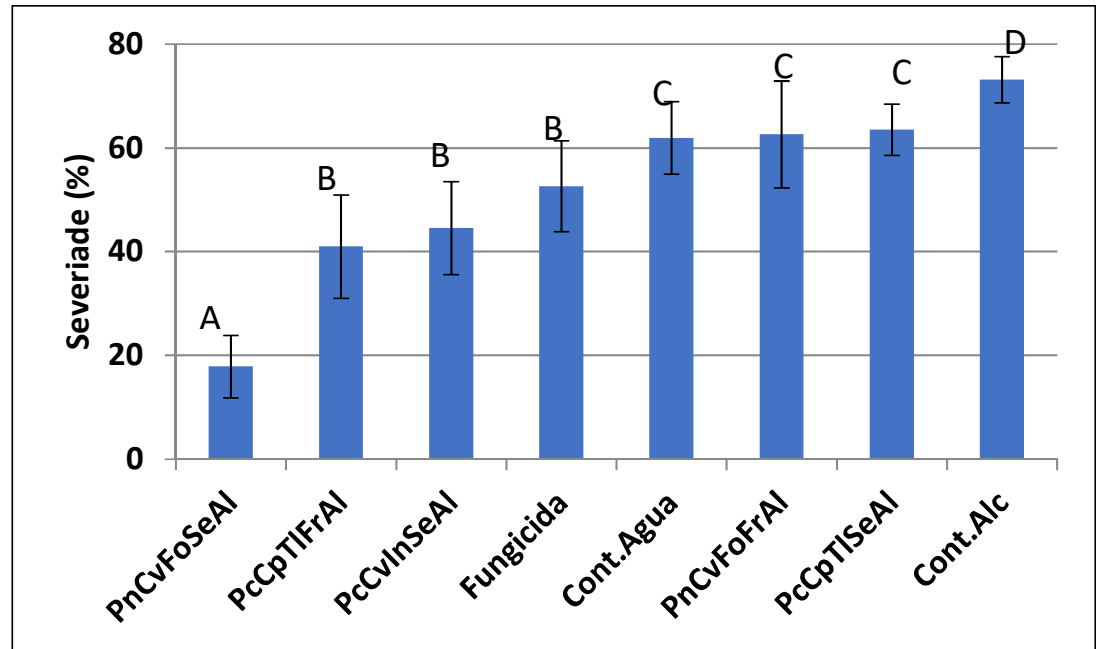

Figura 5: Severidade da mela do feijoeiro avaliado em folhas de feijão inoculadas em gerbox no 20 teste. Valores médios seguidos de mesma letra na coluna não são diferentes baseados no teste Scott-Knott a $5 \%$ de probabilidade. Legenda: Pc: P. carniconnectivum, Pn: P. nigrum; Cv: Casa de vegetação, Cp: Campo; TI: talo, Fo: folha, In: Inflorescência; Se: secos, Fr: frescos; Al: Alcoólico. 
O efeito dos tratamentos que foram capazes de reduzir o progresso da doença reflete no acúmulo da severidade ao longo do tempo quando comparados com o controle fungicida, como pode ser observado nas figuras 6 (teste 1) e 7 (teste 2) determinado pela área abaixo da curva de progresso de doença com todos os valores inferiores ao controle álcool.

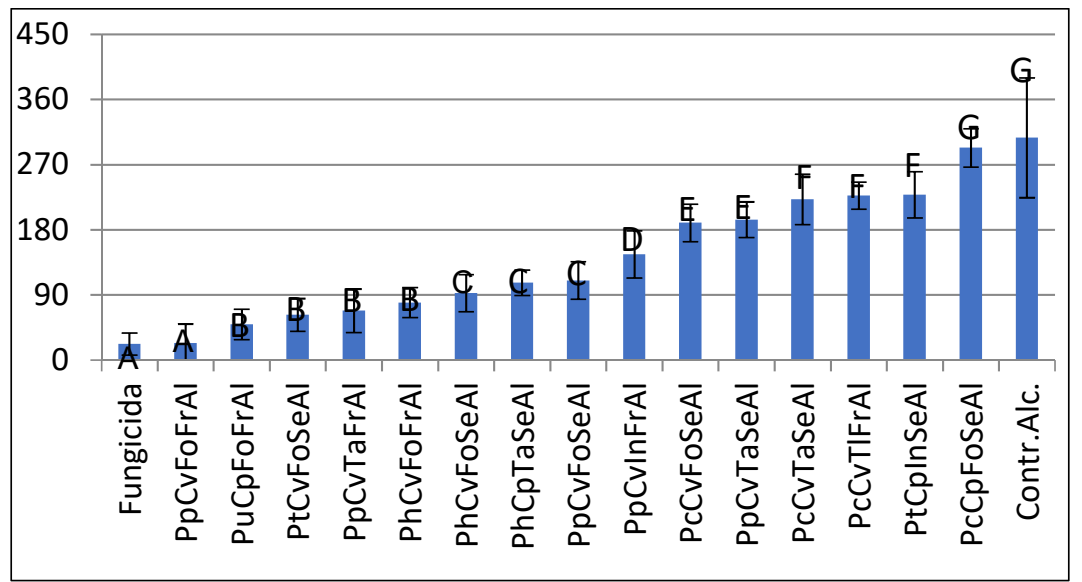

Figura 6: Média da área abaixo da curva do progresso da doença no primeiro teste. Valores médios seguidos de mesma letra na coluna não são diferentes baseados no teste Scott-Knott a 5\% de probabilidade. Legenda: $P p: P$. permucronatum, Pc: P. carniconnectivum, Pn: P. nigrum, Pt: P. tuberculatum; Pu: P. umbellatum, Ph: P. hispidum; Cv:

Casa de vegetação, Cp: Campo; Tl: talo, Fo: folha, In: Inflorescência; Se: secos, Fr: frescos; Al: Alcoólico.

A figura 7 assemelha-se à figura 6, já que essa avaliou a média da área abaixo da curva do progresso da doença no primeiro teste e aquela realizou uma avaliação, proposta ilustrativamente, da média da área abaixo da curva do progresso da doença no segundo teste, sendo assim denominada, a fim de propor os valores.

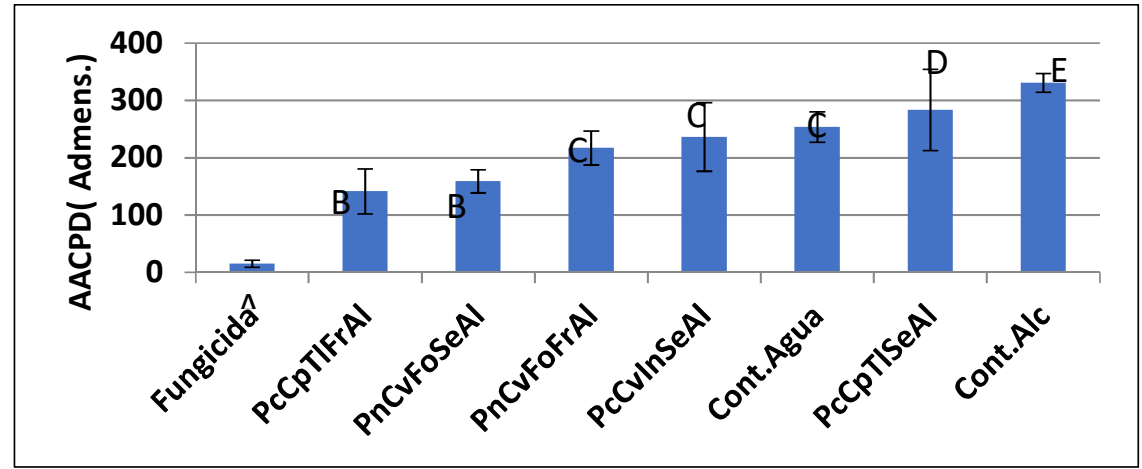

Figura 7: Média da área abaixo da curva do progresso da doença no segundo teste. Valores médios seguidos de mesma letra na coluna não são diferentes baseados no teste Scott-Knott a 5\% de probabilidade. Legenda: Pc: $P$. carniconnectivum, Pn: P. nigrum; Cv: Casa de vegetação, Cp: Campo; TI: talo, Fo: folha, In: Inflorescência; Se: secos, Fr: frescos; Al: Alcoólico.

\section{Ensaios in vivo em câmara úmida}

Para os ensaios in vivo em câmara úmida, foram selecionados os extratos que apresentaram melhores resultados em folhas destacadas. É possível observar uma baixa severidade nos tratamentos com extratos quando comparados com o controle alcoólico, proposto na figura 8, denominada 'Severidade máxima da mela do feijoeiro comum em função do extrato testado em ensaios in vivo. Valores médios seguidos de mesma letra na coluna não são diferentes baseados no teste Scott-Knott a 5\% de probabilidade'. 


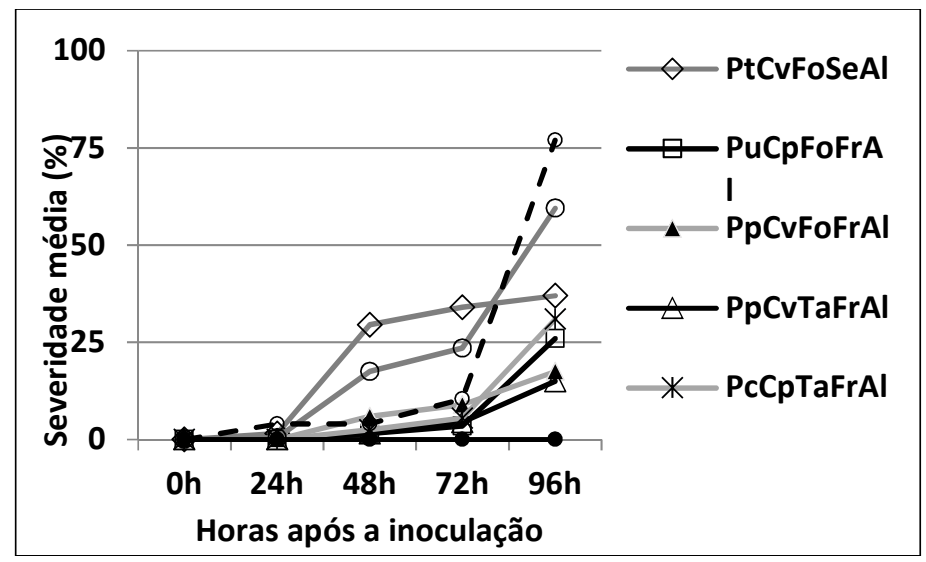

Figura 8: Severidade máxima da mela do feijoeiro comum em função do extrato testado em ensaios in vivo. Valores médios seguidos de mesma letra na coluna não são diferentes baseados no teste Scott-Knott a $5 \%$ de probabilidade. Legenda: Pp: P. permucronatum, Pc: P. carniconnectivum, Pn: P. nigrum, Pt: P. tuberculatum; Pu: P. umbellatum; Cv: Casa de vegetação, Cp: Campo; TI: talo, Fo: folha, In: Inflorescência; Se: secos, Fr: frescos; Al: Alcoólico.

O efeito de inibição dos extratos também pode ser observado quanto ao progresso da doença em que os extratos alcoólicos de talo e folha de $P$. permucronatum, de talo de $P$. carniconnectivum e folha de $P$. tuberculatum apresentaram potencial de controle da doença satisfatório, controlando o progresso da doença quando comparado com o controle álcool (figura 9).

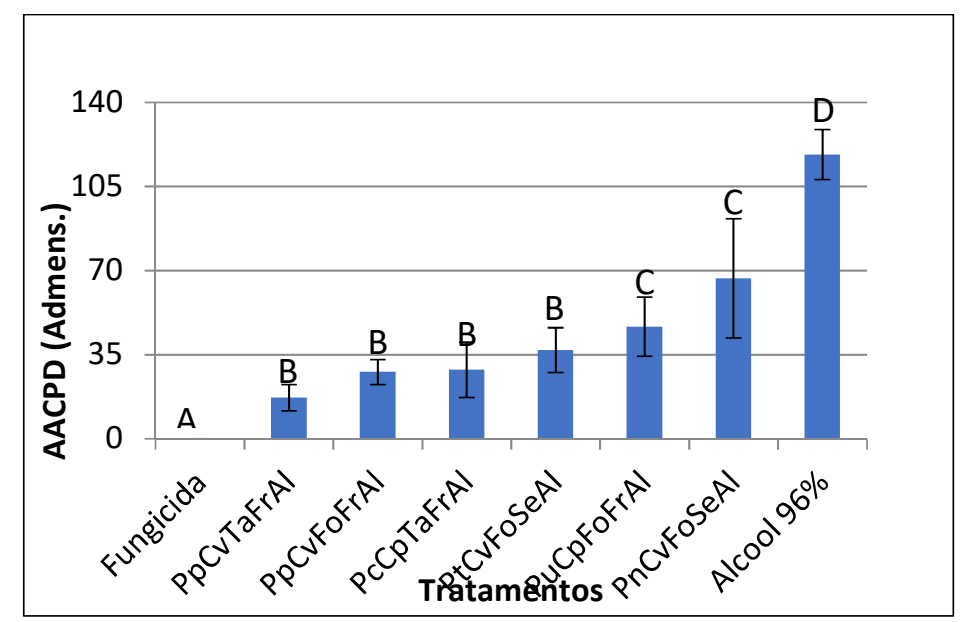

Figura 9: Média da área da curva de progresso da mela do feijoeiro comum em função dos extratos testados em ensaios in vivo. Valores médios seguidos de mesma letra na coluna não são diferentes baseados no teste Scott-Knott a 5\% de probabilidade. Legenda: Pp: P. permucronatum, Pc: P. carniconnectivum, Pn: P. nigrum, Pt: P. tuberculatum; Pu:

P. umbellatum; Cv: Casa de vegetação, Cp: Campo; Tl: talo, Fo: folha, In: Inflorescência; Se: secos, Fr: frescos; Al: Alcoólico.

\section{DISCUSSÃO}

A mela do feijoeiro causada pelo fungo $R$. solani e a podridão do colo causada pelo fungo $S$. rolfsii são doenças limitantes para o cultivo de feijão comum no Brasil. O presente trabalho estudou a possibilidade de controlar os fungos causadores dessas doenças com extratos vegetais de seis espécies do gênero Piper. Do total de extratos testados in vitro, 26 extratos foram eficientes no controle de $R$. solani e dez foram eficientes ao controlarem o crescimento do fungo $S$. rolfsii.

Todas as espécies de Piper utilizadas no estudo, em pelo menos alguma forma de preparação, apresentaram potencial bioativo no controle de crescimento do fungo $R$. solani. Os extratos de $P$. 
permucronatum e $P$. carniconnectivum em suas diferentes formas de preparo foram os que mais inibiram o patógeno. Já com o fungo $S$. rolfsii apenas a espécie $P$. umbellatum não apresentou nenhum tipo de inibição para o patógeno S. rolfsii, em contrapartida quatro diferentes formas de extratos de $P$. hispidum inibiram o crescimento do patógeno.

A ação dos extratos de espécies do gênero Piper já foi descrita em outros estudos. Araújo et al. (2014), ao avaliar extratos das folhas de $P$. marginatum, verificaram que estes foram eficientes no controle do crescimento micelial do fungo Colletotricum scovillei em testes in vitro. Araújo et al. (2014) afirma que possivelmente metabólitos secundários presentes nas espécies do gênero Piper afetam de forma distinta microrganismos fitopatogênicos. Extratos de folhas e frutos de $P$. aduncum também foram eficientes inibindo o crescimento micelial do fungo Sclerotina sclerotium (GARCIA et al., 2012).

As diferenças nas constituições químicas de plantas de Piper podem estar atribuídas a diversidade genética das espécies ocorrendo uma variedade de quimitipos (SILVA et al., 2008), o que pode ser observado com os extratos desse estudo onde foi possível identificar o potencial inibitório frente aos patógenos estudados de algumas espécies e a ineficiência de outras espécies do gênero Piper.

O mesmo pode ser observado quanto aos diferentes tecidos das plantas, que podem apresentar compostos químicos diferentes, o que ocasionou resultados diferentes dos extratos quanto à inibição dos patógenos. Nos ensaios in vitro pode-se analisar que os extratos preparados com os talos das plantas foram mais eficientes, isso pode estar associado aos diferentes constituintes, em concentrações diferentes em todas as partes das plantas (FACUNDO et al., 2008).

Os extratos desse estudo foram mais eficientes quando preparados com materiais secos, o que pode estar relacionado ao fato de a pesagem do material seco ter sido preparado com o material vegetal desidratado, então apesar dos extratos frescos e secos terem sido preparados na mesma proporção $(0,01 \mathrm{mg} / \mathrm{mL})$, a concentração de materiais no último foi maior (ROHDE et al., 2013).

Ao serem submetidos à diluição 12 extratos apresentaram potencial inibitório até a concentração 1:100 para R. solani, desses 9 extratos foram mais eficientes do que o fungicida. As diluições não foram satisfatórias no controle de S. rolfsii, confirmando apenas o potencial dos extratos na maior concentração. O mesmo foi observado com os extratos de Piper amplum Kunt testados para o controle também de $R$. solani e S. rolfsii, em que o extrato apresentou melhor eficiência na maior concentração (FERREIRA et al., 2017).

Testes com extratos de Capsicum sp. afim de verificar o potencial inibitório frente ao crescimento micelial de Rhizoctonia solani, obtiveram melhores resultados com extratos na maior concentração (VIEIRA JUNIOR et al., 2016). Extratos hidroalcóolicos de Allium sativum também apresentaram resultados mais eficientes em testes contra os fungos Bipolares spp. Curvalaria luneta e Fusarium subglutinans, quando em concentrações mais elevadas (COSTA et al., 2017).

No teste in vivo em caixas de Gerbox os extratos foram eficientes no controle da severidade da mela do feijoeiro, destacando-se os extratos alcoólicos de folhas de $P$. permucronatum preparado com materiais vegetais frescos e de $P$. nigrum preparado com materiais vegetais secos cultivados em casa de vegetação, 
que não diferenciaram do controle fungicida. Extratos alcoólicos das folhas de $P$. tuberculatum preparados com materiais vegetais secos, das folhas de $P$. umbellatum e $P$. hispidum preparados com material vegetal fresco, de talo de $P$. permucronatum e de talo e inflorescência de $P$. carniconnectivum a partir de materiais frescos também apresentaram resultados significativos quanto ao controle da severidade da doença quando comparados com o controle alcoólico.

Carmo et al. (2015) ao realizarem experimentos com folhas destacadas e em campo com o fungo Colletotrichum truncatum afirmaram que no experimento em laboratório com folhas destacadas a concentração de esporos empregados nas folhas, ação da luz e umidade, permite com que o aparecimento da doença ocorra de forma mais controlada do que em experimentos em campo, que apresentam um número maior de variações.

Os mesmos extratos que foram capazes de inibir a severidade da mela do feijoeiro nas folhas destacadas também foram capazes de reduzir o progresso da doença, esse efeito reflete no acúmulo da severidade ao longo dos dias que decorreu o experimento, quando comparados com o controle fungicida. Ressaltando que todos os extratos apresentaram área abaixo da curva do progresso da doença menores que o controle negativo.

Quando testados em mudas de feijoeiro os extratos reafirmaram sua eficiência em controlar a mela do feijoeiro quando comparados com o controle alcoólico. Os melhores extratos nesse teste foram os extratos de talo e folha de P. permucronatum e de folha de $P$. umbellatum, preparados com materiais frescos, e folha de $P$. tuberculatum preparado com materiais secos, que apresentaram severidade máxima estatisticamente próxima ao controle fungicida.

Óleos e extratos vegetais de Azadirachta indica ( $\mathrm{nim}$ ) foram testados em ensaios in vivo no controle de oídio do feijoeiro e constatou-se que os mesmos pulverizados horas antes da inoculação do patógeno, diminuíram significativamente o número de manchas e sinais do patógeno nas folhas (CARNEIRO et al., 2007). O mesmo foi observado no presente estudo em que extratos de Piper controlaram os sintomas da mela do feijoeiro quando inoculados $24 \mathrm{~h}$ antes do patógeno.

O efeito inibitório dos extratos também foi observado quanto ao progresso da doença, e novamente os extratos de talo e folha de $P$. permucronatum apresentaram os melhores resultados, juntamente com os extratos de talo de $P$. carniconnectivum e folha de $P$. tuberculatum que controlaram o progresso da doença quando comparado com o controle álcool. Extratos Marmodica charantia (Melão-de-São-Caetano) foram testados no controle de S. rolfsii em testes in vivo, onde constatou-se a diminuição da severidade da doença em $74 \%$. Os autores afirmaram que extratos vegetais podem controlar doenças fúngicas, preferencialmente de maneira preventiva (FARIA et al., 2009). Os extratos do presente estudo mostraram potencial para controle da doença, e podem futuramente serem utilizados também como método preventivo para a doença mela do feijoeiro. 


\section{CONCLUSÕES}

Os extratos vegetais utilizados nesse estudo apontam grande potencial de espécies de Piper para o controle de doenças fitopatogênicas. Dentre os extratos avaliados, os extratos alcoólicos de talo e folha de $P$. permucronatum foram os que se destacaram no controle de $R$. solani, tanto em testes in vitro como em testes in vivo. Nos testes com o fungo S. rolfsii o extrato que melhor inibiu o patógeno foi o extrato aquoso de talo de $P$. tuberculatum. Esses extratos têm potencial para futuramente serem utilizados nos cultivos de feijoeiro comum, sendo necessários testes em campo.

\section{REFERÊNCIAS}

ABRASCO. Associação Brasileira de Saúde Coletiva. Um alerta sobre os impactos dos agrotóxicos na saúde. Rio de Janeiro: ABRASCO, 2012.

ARAÚJO, J. L.; OLIVEIRA, E. S.; TEIXEIRA, F. N.. Controle alternativo in vitro de Sclerotium rolfsii em girassol (Helianthus annuus L.) pelo uso de extratos vegetais e Thichoderma spp. Ciências Agrárias, Sobral, v.15, n.2, p.2535, 2014.

CAMPO, A. A. B.; SCOTTON, J. C.; COSTA, W. L. F.; GIASSI, V.; PINTO, D. F. P.; HOMMA, S. K.. Seleção de fungicidas visando à preservação de fungo micorrízicos arbusculares nativos no cultivo do feijoeiro. Revista Brasileira de Engenharia Agrícola e Ambiental, Campina Grande, v.19, n.9, p.898-902, 2015.

CARMO, M. D. S.; CARVALHO, E. M. S.; GOMES, R. L. F.; LOPES, A. C. A.; CAVALCANTE, G. R. S.. Avaliação de acessos de feijão-fava, para resistência a Colletotrichum truncatum, em condições de folhas destacadas e campo. Summa Phytopathol, v.41, n.4, p.292-297, 2015.

CARNEIRO, S. M. T. P. G.; PIGNONI, E.; VASCONCELLOS, M. E. C.; GOMES, J. C.. Eficácia de extratos de nim para o controle de oídio do feijoeiro. Summa Phytopathol, Botucatu, v.33, n.1, p.34-39, 2007.

CELOTO, M. I. B.; PAPA, M. F. S.; SACRAMENTO, L. V. S.; CELOTO, M. J.. Atividade antifúngica de extratos de plantas a Colletotrichum gloeosporioides. Acta Scientiarum Agronomy, Maringá, v.30, n.1, p.1-5, 2008.

COSTA, G. R.; FILHO, A. C. C.; JUNIOR, M. L.. Controle químico da Mela do Feijoeiro comum. Santo Antônio de Goiás: EMBRAPA, 2008.

COSTA, N. C.; CHAGAS JUNIOR, A. F.; RAMOS, A. C. C.; SOARES, L. P.; SCHEIDT, G. N.. Atividade antimicrobiana e analise fitoquímica preliminar do extrato vegetal de alho no controle de fungos fitopatogênicos. Revista Verde de Agroecologia e Desenvolvimento Sustentável, Pombal, v.12, n.1, p.161-166, 2017.

DHINGRA, O. D.; SINCLAIR, J. B.. Basic Plant Pathology Methods. Boca Raton: CRC Press, 1995.

FACUNDO, V. A.; POLLI, A. R.; RODRIGUES, R. V.; MILITÃO, J. S. L. T.; STABELLI, R. G.; CARDOSO, C. T.. Constituintes químicos fixos e voláteis de talos e frutos de Piper tuberculatum Jacq. e das raízes de $P$. hispidum H. B. K. Acta Amazônica, v.38, n.4, p.733-742, 2008.

FARIA, F. A.; BUENO, C. J.; PAPA, M. F. S.. Atividade fungitoxica de Momordica charantia L. no controle de Sclerotium rolfsii Sacc. Acta Scientiarum Agronomy, Maringá, v.31, n.3, p.383-389, 2009.

FERREIRA, E. F.; JOSÉ, A. R. S.; BONFIM, M. P.; PORTO, J. S.; JESUS, J. S.. Uso de extratos vegetais no controle in vitro do Colletotrichum gloeosporioides Penz. coletado em frutos de mamoeiro (Carica papaya L.). Revista Brasileira de Fruticultura, Jaboticabal, v.36, n.2, 2014.

FERREIRA, T. P. S.; SANTOS, G. R.; FERREIRA, T. P. S.; TEIXEIRA, T. S.; BATISTA, R. D.; LUZ, R. B.; GUIMARÃES, L. G. $L$.. Evaluation of the fungitoxic activity of vegetal extracts on the mycelial growth of phytopathogens. Bioscience jornal, Uberlândia, v.33, n.3, p.566-571, 2017.

FERRIS, H.; ZHENG, L.. Plant sourcers of Chinese herbal remedies: effects on Pratylenchus vulnus and Meloidogyne javanica. Journal of Nematology, Marceline, v.31, p.241263, 1999.

GARCIA, R. Á.; JULIATTI, F. C.; BARBOSA, K. A. G.; CASSEMIRO, T. A. Atividade antifúngica de óleo de extratos vegetais sobre Sclerotinia sclerotiorum. Bioscience Journal, Uberlândia, v.28, n.1, p.48-57, 2012.

LAJOLO, F. M.; GENOVESE, M. I.; MENEZES, E. W.. Qualidade nutricional. In: ARAÚJO, R. S.; RAVA, C. A.; STONE, L. F.; ZIMMERMANN, M. J. O. Cultura do feijoeiro comum no Brasil. Piracicaba: POTAFOS, 1996.

MIORIN, J. D.; CAMPONAGARA, S.; DIAS, G. L.; SILVA, N. M.; VIERO, C. M.. Percepções de agricultores sobre o impacto dos agrotóxicos para a saúde e o meio ambiente. Revista de Enfermagem do Centro Oeste Mineiro, v.6, n.3, p.24102420, 2016.

MIRANDA, L. B.; LIMA, P. R.; MARTINS, G. A. S.; SILVA, W. G.. Water absortption in bean seeds (Phaseolus vulgaris $\mathrm{L}$.) during processing. Boletim do Centro de Pesquisa de Processamento de Alimentos, Curitiba, v.31, n.2, p.285-294, 2013.

NECHET, K. L.; VIEIRA, B. A. H.; Reação de cultivares de feijão: caupi à mela (Rhizoctonia solani) em Roraima. 
Fitopatologia Brasileira, Boa Vista, v.32, n.5, p.424-428, 2007.

RIBEIRO, F. E.; PELOSO, M. J. D.; BARBOSA, F. R.; GONZAGA, A. C. O.; OLIVEIRA, L. F. C.. Recomendações técnicas para o cultivo do feijoeiro-comum (Phaseolus vulgaris L.) nas regiões norte e nordeste do país. Santo Antônio de Goiás: EMBRAPA, 2011.

ROHDE, C.; MOINO JÚNIOR, A.; SILVA, P. K.; RAMALHO, K. R. O.. Efeito de extratos vegetais aquosos sobre a mosca-dasfrutas Ceratitis capitata (Wiedemann) (Diptera: Tephritidae). Arquivos do Instituto Biológico, v.80, n.4, p.407-415, 2013.

SANTOS, C. A. B.; SILVA, A. P. M.. Extratos vegetais de plantas daninhas contra o pulgão Aphis craccivora koch 1854, no feijão Vigna unguiculata (I.) Walp. Revista IberoAmericana de Ciências Ambientais, Aquidabã, v.6, n.2, p.6975, 2015.

SANTOS, T. G.; REBELO, R. A.; DALMARCO, E. M.; GUEDES, A.; GASPER, A. L.; CRUZ, A. B.; SCHMIT, A. P.; CRUZ, R. C. B.; STEINDEL, M.; NUNES, R. K.. Composição química e avaliação da atividade antimicrobiana do óleo essencial das folhas de
Piper malacophyllum (C. Presl.) C. DC. Química Nova, v.35, n.3, p.477-481, 2012.

SARTORATO, A.; RAVA, C. A.. Principais doenças do feijoeiro comum e seu controle. Goiânia: EMBRAPA, 1994.

SILVA, J. L.; SOUZA, P. E.; MONTEIRO, F. P.; FREITAS, M. L. O.; SILVA JÚNIOR, M. B.; BELAN, L. L.. Antifungal activity using medicinal plant extracts against pathogens of coffee tree. Revista Brasileira de Plantas Medicinais, v.16, n.3, p.539544, 2014.

SILVA, R. J. F.; AGUIAR-DIAS, A. C. A.; FAIAL, K. C. F.; MENDONÇA, M. S.. Caracterização farmacognóstica de Piper arboreum var. arboreum e $P$. tuberculatum (Piperaceae). Acta Amazônica, v.46, n.2, p.195-208, 2016.

VALE, F. X. R.; ZAMBOLIM, L.. Controle de doenças de plantas: grandes culturas. Viçosa: UFV, 1997.

VIEIRA JÚNIOR, J. R.; FERNANDES, C. F.; ALVES, R. C.; FONSECA, A. S.; FREIRE, T. C.. Extratos de pimentas (Capsicum spp.) para inibição do crescimento micelial in vitro de Rhizoctonia solani Kuhn. Enciclopédia Biosfera, Goiânia, v.13, n.23, p.1805-1814, 2016.

A CBPC - Companhia Brasileira de Produção Científica (CNPJ: 11.221.422/0001-03) detém os direitos materiais desta publicação. Os direitos referem-se à publicação do trabalho em qualquer parte do mundo, incluindo os direitos às renovações, expansões e disseminações da contribuição, bem como outros direitos subsidiários. Todos os trabalhos publicados eletronicamente poderão posteriormente ser publicados em coletâneas impressas sob coordenação da Sustenere Publishing, da Companhia Brasileira de Produção Científica e seus parceiros autorizados. Os (as) autores (as) preservam os direitos autorais, mas não têm permissão para a publicação da contribuição em outro meio, impresso ou digital, em português ou em tradução. 